\title{
DESAFIO DA ODONTOPEDIATRIA NO DIAGNÓSTICO DA DOENÇA MÃO, PÉ E BOCA: RELATO DE CASO
}

\author{
Ianara Vitória Souza de Lucena I \\ Cecília Pacheco Calado ${ }^{\prime}$ \\ Herrison Félix Valeriano da SILVA I \\ * Jainara Maria Soares Ferreira"
}

\section{RESUMO}

A doença mão, pé e boca é uma enterovirose (Coxsackie A16 ou Enterovírus 71) frequente na infância. Possui relevância na Odontopediatria devido a presença de estomatite, sendo importante o conhecimento sobre diagnóstico e tratamento, viabilizando melhora no quadro de saúde bucal. O artigo objetivou relatar um caso clínico de um bebê que contraiu a doença mão, pé e boca, relatando os sinais clínicos mais frequentes e o tratamento sintomático em nível de Odontopediatria. Paciente masculino, 1 ano e 2 meses, compareceu a Odontopediatria apresentando no exame físico: febre alta, manchas vermelhas, vesículas branco-acinzentadas e ulcerações dolorosas na boca, amígdalas e faringe, associadas a relato materno de disfagia. Além de pequenas bolhas e úlceras nas palmas das mãos e plantas dos pés, quadro que durou 6 dias. Para tratamento dos sintomas, foi prescrito VASA (violeta genciana $600 \mathrm{mg}$, xilestesin $2 \% 1,5 \mathrm{ml}$ sem vasoconstrictor, sacarina e água), objetivando melhora da disfagia; analgésico (paracetamol bebê $100 \mathrm{mg} / \mathrm{ml}$ suspensão), devido ao quadro doloroso e febril e orientou-se dieta especial (líquida, pastosa, fria e sem condimentos) e higiene bucal. Conclui-se que a doença mão, pé e boca é benigna, autolimitada, que raramente evolui com complicações. $O$ tratamento da infecção não complicada é feito ambulatoriamente com sintomáticos. O caso relatado recebeu apenas tratamento sintomático e sem complicações, com boa evolução.

PALAVRAS-CHAVE: Estomatite. Odontopediatria. Infecções por Enterovirus.

Graduandos em Odontologia. Faculdade de Enfermagem Nova Esperança, FACENE. Departamento de Odontologia. CEP: 58067698, João Pessoa, Paraíba, Brasil. ORCID ID: 000-002-4511-2925; 000-0003-4898-6210; 000-0001-6714-3151.

Doutora em Odontopediatria. Faculdade Nova Esperança, FACENE. Departamento de Odontologia. CEP 58067695, João Pessoa, Paraíba, Brasil. *Autor correspondente: jainara.sf@gmail.com Orcid: 0000-0001-7040-7197. 


\section{INTRODUÇÃO}

A doença mão, pé e boca (DMPB) é uma entrevirose causada especialmente pelos vírus Coxsackie A16 ou Enterovírus 71, de transmissão oro-fecal, e por contato com secreções orofaringeas frequentemente observada na infância, antes dos cinco anos de idade. 1,2,3 A literatura apresenta a patologia como facilmente reconhecível quando apresentada em sua forma clássica: erupção cutânea associada a febre e enantema e, às vezes, onicomadese (destacamento indolor e espontâneo da unha) e linhas de Beau (sulcos horizontais que surgem nas unhas quando seu corpo para de produzir novas células por um tempo), cerca de 40 dias após a doença aguda. ${ }^{1,3}$

Há uma maior frequência da DMPB em pacientes com o a 4 anos e costuma aparecer mais comumente no verão e no outono, bem como em áreas tropicais. ${ }^{1,4}$ É caracterizada por lesões cutâneas, com bolhas ou vesículas, começa com mal-estar geral e odinofagia (dor durante a deglutição de alimentos ou líquidos), seguidos de febre, dor na boca, dor abdominal e sintomas respiratórios. ${ }^{1,6}$ A erupção cutânea mucocutânea típica é caracterizada por um enantema constituído por vesículas ou úlceras na mucosa oral, apresentando-se como manchas vermelhas com bolhas que se tornam ulceradas mais comumente na língua, gengivas e no interior das bochechas cobertas por uma pseudomembrana amarelada, cercada por um halo eritematoso. 4,6

As lesões cutâneas podem ocorrer após as lesões bucais, são papulo-vesiculares, ocorrendo nas extremidades distais dos membros, mãos, pés, nádegas e região da fralda, inicia maculo-papular e evolui rapidamente para vesículas cinzas de 3 a 7 $\mathrm{mm}$, com halo avermelhado, oval, linear ou crescente. Estão dispostas nas faces lateral e dorsal dos dedos das mãos e dos pés, na região periungueal e nas palmas das mãos e plantas dos pés. 4,6

O seu período de incubação é de 4 a 6 dias, sendo considerada uma doença leve com diagnóstico geralmente clínico. Para a maioria dos pacientes ocorre recuperação entre 6 a 10 dias, sem tratamento médico, e as lesões geralmente cicatrizam sem deixar sequelas.1,2,6 Não é comum haver complicações, porém quando ocorrem podem ser graves, especialmente em neonatos e crianças pequenas, com acometimento do sistema nervoso central e dos músculos, causando complicações como meningite asséptica, encefalite, miosite e miocardite, o risco de infecção pode ser reduzido apenas pela boa higiene com o uso da clorexidina a $12 \%{ }^{2}, 3,4,6,7,8$

O seu tratamento se baseia na administração de analgésicos, hidratação oral e vigilância dos sinais e sintomas de possíveis complicações. As bolhas na boca das crianças geralmente causam perda de apetite, incluindo a interrupção da ingestão de água potável, portanto, o monitoramento adequado. ${ }^{2,6}$ Neste sentido, a doença possui especial interesse na Odontopediatria por apresentar, dentre seus sinais clínicos, a estomatite, sendo importante o cirurgiãodentista conhecer sobre o diagnóstico e o tratamento sintomático desta afecção, oportunizando melhora na evolução do quadro de saúde bucal da criança.

Diante do exposto, este trabalho objetivou relatar um caso clínico de um paciente de 1 ano e 2 meses que contraiu a doença mão, pé e boca, informando os sinais clínicos mais frequentes e o tratamento sintomático em nível de Odontopediatria. 


\section{MATERIAL E MÉTODOS}

Relato de caso clínico de uma criança de 1 ano e 2 meses, atendida em clínica particular de Odontopediatria na cidade de João Pessoa (PB) no ano de 2019. Como instrumento de coleta de dados foi realizada entrevista com familiares e análise do prontuário. Os dados foram analisados num enfoque qualitativo e discutidos posteriormente mediante literatura científica sobre o tema. Este estudo foi aprovado pelo Comitê de Ética em Pesquisa local (CAAE 33788020.9.0000.5176) e utilizaram-se os pressupostos da Resolução 466/2012 CNS, que trata de pesquisas e testes em seres humanos, como também do Código de Ética Odontológico.

\section{RELATO DE CASO}

Paciente de gênero masculino, 1 ano e 2 meses, compareceu a Odontopediatra apresentado os seguintes sinais constatados ao exame físico: febre alta, manchas vermelhas na boca, amígdalas e faringe com vesículas branco-acinzentadas e ulcerações dolorosas
(Figura 1), além de erupção de pequenas bolhas e úlceras nas palmas das mãos e nas plantas dos pés. A mãe relatou ainda ter observado disfagia no bebê. O quadro sintomático durou 6 dias.
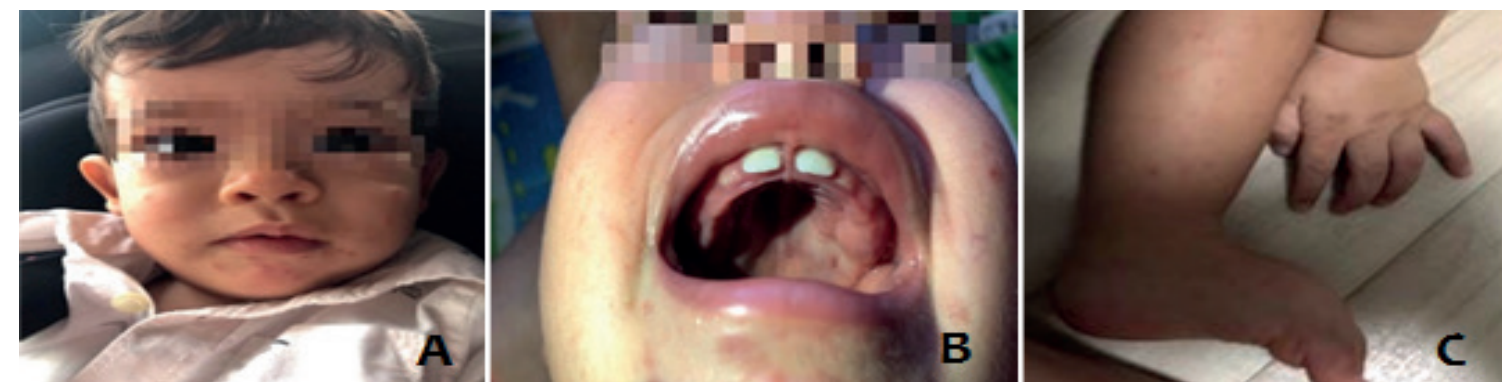

FIGURA 1: Aspecto extra (A) e intrabucal (B), pés e mãos do paciente (C), diagnosticado pela doença mão, pé e boca (DMPB). João Pessoa, PB (2019).

Para tratamento sintomático da estomatite foi prescrito o VASA (Figura 2) composto por violeta genciana (600 mg), xilestesin $2 \%(1,5 \mathrm{ml})$ sem vasoconstrictor, sacarina e água, manipulado em farmácia, no sentido de oportunizar melhora da alimentação da criança. A prescrição de analgésico (paracetamol bebê $100 \mathrm{mg} / \mathrm{ml}$ suspensão) também se fez necessária devido ao quadro doloroso e febril. Orientações adicionais foram realizadas com relação a higiene bucal e recomendação de dieta líquida e pastosa, fria e sem condimentos. 


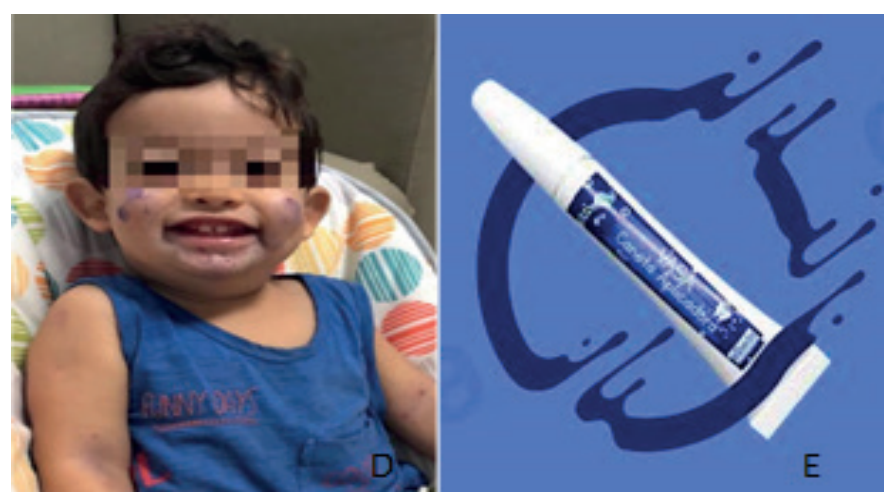

FIGURA 2: Aspecto clínico (D) após aplicação do VASA (E) no paciente diagnosticado pela doença mão, pé e boca (DMPB). João Pessoa, PB (2019).

\section{DISCUSSÃO}

A DMPB como uma patologia exantemantosa de ocorrência comum na infância e de maior predomínio em áreas tropicais e durante estações como outono e verão, especialmente em áreas tropicais, como no Brasil, e em especial da região Nordeste, em que ocorreu o presente caso, tornando a população infantil deste local ainda mais sujeita a esta infecção. 2,3,4

Outro dado de importância epidemiológica apresentado pela literatura é a fácil disseminação e contágio da doença, relacionada a sua forma de transmissão (a partir do contato interpessoal ou orofecal), em especial nas crianças, tendo em vista o seu amplo contato com outros indivíduos da mesma faixa etária.3,4,5 No caso apresentado, é verificada a validade desta constatação, devido ao provável ambiente e oportunidade de contágio ter ocorrido em berçário em que o paciente frequentava, durante o manuseio de brinquedos coletivos, ou até mesmo no momento da troca de fraldas.

Com relação a faixa etária, a literatura informa que essa patologia pode acometer crianças e adultos, porém sendo mais comum durante a infância, entre o a 4 anos, ${ }^{1,4,5}$ como observado no caso analisado no presente artigo, no qual o paciente encontra-se com idade de 1 ano e 2 meses.

As manifestações clínicas da DMPB são geralmente brandas, iniciando, frequentemente, de forma abrupta com febre, falta de apetite, mal estar e dor de garganta. Em geral, as úlceras bucais desenvolvem-se após um ou dois dias do aparecimento da febre, a partir de pequenas manchas vermelhas com bolhas que se tornam ulceradas, com surgimento mais comum na língua, gengivas e no interior das bochechas, associadas a erupções cutâneas que, em geral, não apresentam prurido e se localizam frequentemente nas palmas das mãos e solas dos pés. ${ }^{1,9}$ Estas colocações corroboram com os achados clínicos observados no caso em tela, tais como febre, manchas e vesículas nas topografias mais comumente relatadas, além de bolhas e úlceras em palmas das mãos e planta dos pés.

Em algumas raras situações a DMPB pode apresentar complicações importantes de origem neurológica e cardiovascular, sendo importante observar o quadro geral do paciente. $2,7,8$ Entretanto, em estudo 
realizado em $2013^{6}$ foi relatado que o problema mais comum na DMPB é a desidratação secundária a odinofagia intensa causada por úlceras orais dolorosas, devendo ser administrado analgésico para alívio das queixas e reforçada a necessidade da hidratação oral (preferencialmente a ingestão de líquidos frios que são analgésicos). Para o caso clínico analisado, foi recomendada a realização de dieta líquida, pastosa, fria, sem condimentos e evitando alimentos ácidos, para alívio da odinofagia e consequentemente melhora na capacidade de se alimentar e hidratação, evitando complicações devido a desidratação. Dessa forma, a conduta dietética colabora com os achados da literatura que reforçam a importância de uma dieta com líquidos frios e sem bebidas gasosas ou ácidas, gerando melhora do quadro de dor devido as úlceras bucais. 4

O diagnóstico de DMPB é clínico e não requer testes suplementares. Não obstante, se for necessário um diagnóstico confirmatório, a PCR pode ser realizada em amostras de orofaringe, pele, sangue ou fezes. Apenas $15 \%$ das culturas virais são positivas. Os testes para identificar sorotipos de IgM específicos podem ser úteis em alguns casos. ${ }^{1,3,4}$ o período de incubação varia de

\section{CONSIDERAÇÕES FINAIS}

Os exantemas virais são comuns na infância, apesar da maioria ser inofensiva, é necessária a vigilância dos sinais e sintomas a fim de prevenir possíveis complicações. A DMPB é doença benigna, autolimitada, que raramente evolui com complicações. $O$
4-6 dias com duração aproximada de 7-10 dias sem intervenção médica. ${ }^{2}$ Estas informações são compatíveis com nosso estudo, uma vez que o paciente analisado não necessitou de testes laboratoriais, com duração aproximada de 6 dias e alívio sintomático, associado ao uso de tratamento, corroborando com o entendimento da patologia como autolimitada e com baixa taxa de complicações.

Com relação ao tratamento, é importante usar o tratamento sintomático para alívio principalmente da dor e da febre, com uso de analgésicos e antitérmicos, excetuando-se os raros casos com possíveis complicações, em que se faz necessário internação do paciente e possibilidade de utilização de aciclovir e imunoglobulina. ${ }^{1,9}$

A conduta realizada no caso clínico avaliado condiz com a literatura, tendo em vista que a criança apresentava-se com bom estado geral, sem necessidade de internamento, ou sinais de complicações. Fezse uso de medicação analgésica e antitérmica, paracetamol, com redução da febre e alívio da dor, além disso, realizou-se uso do composto manipulado VASA, de forma tópica, colaborando para alívio sintomático e evitando possíveis complicações em decorrência da odinofagia. tratamento da infecção não é complicado, pode ser feito ambulatorialmente com sintomáticos. O caso relatado recebeu apenas tratamento sintomático e sem complicações, com boa evolução. 


\title{
THE CHALLENGE OF PEDIATRIC DENTISTRY IN THE DIAGNOSIS OF HAND, FOOT AND MOUTH DISEASE: CASE REPORT
}

\begin{abstract}
Hand, foot and mouth disease (HFMD) is an enterovirus (Coxsackie A16 or Enterovirus 71) common in childhood. It has relevance in Pediatric Dentistry due to the presence of stomatitis, and knowledge about diagnosis and treatment is important, enabling improvement in oral health. The article aimed to report a clinical case of a baby who catch hand, foot and mouth disease, reporting the most frequent clinical signs and symptomatic treatment at the level of Pediatric Dentistry. Male patient, 1 year and 2 months old, attended Pediatric Dentistry showing on physical examination: high fever, red spots, grayish-white vesicles and painful ulcerations in the mouth, tonsils and pharynx, associated with a maternal report of dysphagia. In addition to small blisters and ulcers on the palms and soles, a picture that lasted 6 days. For the treatment of symptoms, VASA was prescribed (gentian violet $600 \mathrm{mg}$, xylestesin $2 \% 1.5 \mathrm{ml}$ without vasoconstrictor, saccharin and water), aiming at improving dysphagia; analgesic (paracetamol baby $100 \mathrm{mg} / \mathrm{ml}$ suspension) due to the painful and feverish condition and diet (liquid, pasty, cold and without spices) and oral hygiene were oriented. It is concluded that BMPD is a benign, self-limiting disease, which rarely evolves with complications. The treatment of uncomplicated infection is done on an outpatient basis with symptomatic patients. The reported case received only symptomatic and uncomplicated treatment, with good evolution.
\end{abstract}

KEYWORDS: Stomatitis. Pediatric Dentistry. Enterovirus Infections.

\section{REFERÊNCIAS}

1. Coronel-Perez IM, Porras-Gonzdlez A, Rodriguez-Rey EM, Croche-Santander B. Enfermedad boca-mano-pie atípica infantil con rasgos de eczema herpetico y de acrodermatitis. Arch. Argent. Pediatr. 2019; 117(1): 59-62.

2. Vallina LSC, Caballero AM, Lin HT. Enfermedad de boca, mano, pie en un lactante. MediSan. 2019; 23(1): 106-13.

3. Russo DH, Luchs A, Machado BC, Carmona RDC, Timenetsky MDCS. Echovirus 4 associated to hand, foot and mouth disease. Revista do Rev. Inst. Med. Trop. Sao Paulo. 2006; 48(4): 197-99.

4. Tamayo MRR, Aldana MS, González OAI, Suros YP, Llovet NG. Síndrome manos, pies, boca. Casos atendidos en el cuerpo de guardia.
MULTIMED. 2020; 24(1): 140-53.

5. Wang J, Hu T, Sun D, Ding S, Carr M, Xing W, et al.. Epidemiological characteristics of hand, foot, and mouth disease in Shandong, China, 2009-2016. Sci Rep. 2017; 7(1): 1-9.

6. Dantas A, Oliveira MJ, Lourenço O, Coelho PB. Doença mão-pé-boca no adulto: a propósito de um caso clínico. Rev. Port. Med. Geral Fam. 2013; 29(1): 62-65.

7. Ribeiro BB, Guerra LM, Galhardi WMP, Cortellazzi KL. Importância do reconhecimento das manifestações bucais de doenças e de condições sistêmicas pelos profissionais de saúde com atribuiçãa de diagnóstico. Odonto. 2012; 1(1): 61-70. 


\section{revista de
ciências \\ da saúde ESPERANÇA}

8. Nakao PH, Terra DP, BALDO ME, Gaetti Jardim EC. Doença mão-pé-boca no atendimento odontopediátrico. Arch Health Invest. 2019; 8(12): 825-31.

9. Li T, Yang Z, Liu X, Kang Y, Wang M. Hand-
VOLUME 18 - NÚMERO 3 - Dez/2020 ISSN ELETRÔNICO 2317-7160

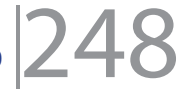

foot-and-mouth disease epidemiological status and relationship with meteorological variables in Guangzhou, southern China, 2008-2012. Rev. Inst. Med. Trop. Sao Paulo. 2014; 56(6): 533-39. 